\title{
Empirical Investigation of the Effects of Water Quality on Concrete Compressive Strength
}

\author{
Obi Lawrence E. \\ (Ph.D, M.Eng, B.Eng, N.C.E.Tech.) \\ Civil Engineering Dept, Imo State University, P.M.B. 2000, Owerri, Nigeria
}

\begin{abstract}
This research empirically investigated on how the compressive strength of concrete can be affected when they were produced with water of different qualities and sources. The water collected was of different qualities and sources and presented as salt water from Abonema, runoff water from University farm catchment and fresh water from Onumiri Spring water. The chemical compositions of these water qualities were analysed while 48 concrete cubes were produced at a ratio of 1:2:4 using each water quality type. The cubes were cured and crushed at 7, 14, 21 and 28 days with the resulting compressive strength. It was observed that the concrete produced with salt water and run-off water had their compressive strengths gradually increased in 7 days but decreased drastically at 14 and 21days age. However, concrete cubes obtained from fresh water gained appreciable strength with age. With the result of this research, it is recommended that fresh water and water without obvious concrete-inimical substances are used in concrete batching.
\end{abstract}

Keywords: compressive strength, water, quality, concrete, aggregates, water cement ratio

\section{INTRODUCTION}

Cement as a binder that holds and forms a strong bond with other composite materials concrete such as fine and coarse aggregates. The binding power of cement can only be activated through the application of water. Water is regarded as an indispensable ingredient as the hydration of cement is possible only in its presence. The quality of mixing water may affect the setting, hardening and strength of concrete. Great control on properties of cement and aggregate is exercised, but the control on the quality of water is often neglected.

The strength and serviceability of structures depend much on the properties of concrete with which the structure is constructed. Concrete as a composite inert material comprising of a binder course (e.g. cement), mineral filler (body) or aggregates and water. Aggregates on the other hand are of two categories namely fine aggregates (e.g. sand) and coarse aggregates (e.g. gravel or crushed stone). The aggregates are usually graded from fine sand to stones of say $20 \mathrm{~mm}$ in diameter depending on the job to be executed.

\subsection{Water Quality in Concrete Production}

Water approved for drinking is generally satisfactory for usage in concrete production, but there are exceptional cases, for instance, in some arid areas, where local drinking water is saline and may contain an excessive amount of chloride, undesirable amount of alkali carbonates and bicarbonates, which could contribute to the alkali silica reaction (Neville, 1996). However, some water that is not for drinking may be fitted or suitable for concrete production (Portland cement Association, 2005). Gupta et al (2012) opined that water with pH range of 6.0 to 8.0 is good for concreting. For hand mixing, a water cement ratio of 0.6 is recommended. When the concrete has to be pumped into position the water cement ratio may be increased to 0.7 . Using water with high content of suspended solid needs to be done with caution and should be allowed to stand in a settling basin before use, a turbidity limit of 2000ppm has been suggested by U.S Bureau of reclamation (1975). Natural water that are slightly acid are harmless, but water containing humid or other organic acids may adversely affect the hardening of concrete (Neville, 1996),

Sea water generally contains 3.5 salinity but slightly accelerates the setting time of cement. This salinity contains about $78 \%$ sodium chloride $15 \%$ chloridesand sulphates of magnesium. The presence of chlorides in concrete containing embedded steel can lead to steel corrosion (Gupta et al, 2012). 
Al-Manaseer et al (1988) showed that water containing very percentages of salt of sodium, potassium, calcium and magnesium used in making concrete containing Portland cement blended with fly ash did not affect the strength of concrete. Chatveera et al. (2006) utilized and recycled sludge water as mixing water for concrete production and found that concrete slump and strength reduced drastically. The carbonate sand bicarbonates of potassium and sodium affect setting time of concrete. The presence of sodium carbonate accelerates the setting time of concrete while bicarbonates may either accelerate or retard the setting time.

Water serves the following purpose

1. To wet the surface of aggregates to develop adhesion because the cement pastes adheres quickly and satisfactory to the wet surface of the aggregates than to a dry surface.

2. To prepare a plastic mixture of the various ingredients and to impact workability to concrete to facilitate placing in the desired position.

3. Water is also needed for the hydration of cementing materials to set and harden during the period of curing.

The quality of water in the mix plays a vital role on the strength of the concrete. Some water which have adverse effect on hardened concrete sometimes may not be harmless or even beneficial during mixing, so clear distinction should be made between the effect on hardened concrete and the quality of mixing water.

\subsection{Aggregates}

Usually, in concrete, aggregates occupy $70-75 \%$ of the total volume of the concrete mass. Initially, aggregates were used as inert filler in concrete production. In actual sense aggregate is not inert filler as it possesses physical, chemical and thermal properties which influence the performance of concrete to a large extent. Aggregates are categorized as fine aggregates and these include sand and very rarely quarry dust, and coarse aggregate which are gravel and crashed stone. Aggregates wield enormous impact on concrete as it determines its strength, durability and structural capacity. For effective performance of concrete, the aggregates must be clean, hard, tough, strong, durable and of properly graded.

\subsection{Concrete Mixing}

Concrete can be defined as a composite material made of cement, water, fine and coarse aggregates with admixtures at times. Concrete mixing also known as batching can be achieved by weight or volume. Well-designed concrete mix is normally executed by weight. In concrete mixing the ratio of the cement, fine aggregates and coarse aggregates are properly designed and followed. Concrete mixing is often called batching can be achieved through manual or mechanical means. Concrete is designated by its characteristic strength and the higher quantity of cement in a mix gives such a concrete high quality. A typical instance is a mix ratio of $1: 2: 4$ or $1: 1 \frac{1}{2}: 3$, the higher the quality of cement in the entire mass the stronger the concrete. Thus, a 1:11/2:3 concrete should be of higher quality than 1:2:4 concrete. The mix for a reinforced concrete should be a minimum of 1:2:4. A mixed ratio of 1:3:6 can be used in mass concrete e.g. for blinding or for over site concrete.

Even though the basic requirement for water for concreting is its portability, the question that comes to mind is the availability of potable water for concreting. In developing countries, provision of water to meet domestic demand has not been fulfilled. In urban areas of Nigeria such as Ibadan, Lagos, Kano, Aba, Onitsha, Owerri and Port Harcourt, only few percentages of the population have access to potable or wholesome water. The water treatment plants in those cities are not adequate to produce the water needed. Those plants are producing below installation capacities due to inadequate power supply and other problems. If the potable water available cannot meet the domestic requirement, it will be difficult for an average contractor to comply with the requirement for mixing water in contract document. The contractors would seek for alternative means by using available surface water once it is clean, clear and of little or no odor for concrete work without testing its suitability.

\subsection{Action of Run-off Water and Fresh Water}

The characteristics of water used in mixing concrete must be such that the chemical reactions, which take place during the setting time of the cement, are not impaired. In general, potable water is highly recommended for concreting. Run-off-water normally contains suspended solid (e.g. silt soil particles) 
and when used in the production of concrete, it tends to increase the strength of concrete at the early stage precisely at 7 days and 14 days of curing but at the latter stage when the impurities present in the run-off start attacking the concrete which will lead to loss of strength. Run-off water which contained suspended solid must be allowed to settle in the settle basin before it is used for concrete. Thus, the water should be free from impurities such as suspended solid, organic matters and salts etc. which may affect the setting of the cement.

It has been established that fresh water and distilled water tends to be constant in their effect on concrete compressive strength at the early stage but at the later stage their strength increases without any adverse drastic effect. It is therefore encouraged using water free from impurities at least potable water for concreting.

\subsection{Quality Control in Concrete Production}

In order to achieve durability, serviceability and any other purpose for a structure, concrete mixed at the site requires special quality control which should be carried out during preparation, batching, mixing and placing of tile concrete mix. The quality control of concrete aims at producing a uniform material which provides properties particularly desirable for work. The basic reason for quality control includes ensuring that workmanship does not fall below a certain specified standard and limiting the overall variations in the quality of the concrete. Poor quality in concreting is traceable to the following factors:

\section{Poor mixing}

2. Variation in batching

3. Substandard cement

4. Inadequate compaction

\section{Insufficient and Lack of curing}

When concrete mixing is completed, test must be conducted to verify workability either by the slump test or by the compacting factor test. The crushing strength of the concrete is obtained by cube test method. The cubes usually $150 \mathrm{~mm} \times 150 \mathrm{~mm} \times 150 \mathrm{~mm}$ or $100 \mathrm{~mm} \times 100 \mathrm{~mm} \times 100 \mathrm{~mm}$ are adequately compacted and cured under laboratory conditions. Such cubes are then crushed at the ages of 7 days, 12 days, 21 days and 28 days and the strength noted.

\subsection{Compressive Strength of Concrete}

The compressive strength is a unique property of concrete and it can be easily determined. The compressive strength of concrete is taken as the maximum compressive load it can carry per unit area. Concrete strength of up to $80 \mathrm{~N} / \mathrm{mm}^{2}$ can be achieved by selective use of the type of cement, mix proportions, method of compaction and curing conditions. Compressive strength of concrete is used as a measure of overall quality of the concrete and therefore an indication of other properties relating to determination of durability.

\section{Methodology}

\subsection{Sample Preparation}

For sample preparation well graded granite coarse aggregates of maximum size $19 \mathrm{~mm}$ were obtained from a granite quarry site and stockpiled. Fine aggregates were obtained and they were air dried and stockpiled. Ordinary Portland cement was purchased for the research work. Laboratory moulds made of steel of sizes $150 \mathrm{~mm} \times 150 \mathrm{~mm} \times 150 \mathrm{~mm}$ were used with the inside coated with oil.

Water for the research was collected in the month of September when the chemical concentration is expected to be at its peak at a designated point in the Abonnema River and labeled salt water while water collected from Onumiri Spring was labeled fresh water and the water from IMSU Farm Catchment was labeled run-off Measured quantity of distilled water was bought from the market and used for the production of controlled concrete cubes.

\subsection{Concrete Production}

The mix ratio used in the production of all the cubes is $1: 2: 4$. The batching was done by weighing. The mixing of concrete was manually done at cement water ratio of 0.5 . Concrete cubes production 
Obi Lawrence E.

was carried out in accordance with BS 1881: part 108:1983. Each layer of concrete received 35 strokes of a $25 \mathrm{~mm}$ square steel runner. The cubes were 48 in number and were properly cured.

\subsection{Compressive Strength Test}

The cured cube was placed with the cast faces in contact with the platens of the universal testing machine electrically operated. In accordance with BS 1881: part 116:1983; the load on the cube was applied at constant rate of stress equal to $0.26 \mathrm{pa} / \mathrm{sec}$. The force or load that resulted to failure of each cube was taken and used in calculating the compressive strength. The test was carried out at the end of 7days, 14days, 21days, and 28days of concrete curing.

\subsection{Water Samples Analyses}

The parameters of the sampled water which were monitored included Sodium Na, Potassium K, Calcium $\mathrm{Ca}$, Sulphate $\mathrm{SO}_{4}{ }^{2}$, Nitrate $\mathrm{NO}_{3}^{-}$, Carbonate $\mathrm{CO}_{3}^{-}$, Bicarbonate $\mathrm{HCO}_{3}^{-}$, Chloride $\mathrm{CL}^{-}$, Fluoride $\mathrm{FL}^{-}$, Phosphate $\mathrm{PO}_{4}^{-}$, Iron Fe, Acidity, $\mathrm{pH}$, Manganese levels amongst others. The acidity levels of water samples were obtained by titrating a known quantity of tested sample with barium hydroxide.

\section{RESUltS AND DisCUSSION}

\subsection{Empirical Results}

\subsubsection{Results of Water Sample Analysis}

The results of laboratory test of the water samples are shown in Table 1

Table1. Water Test Results

\begin{tabular}{|l|l|l|l|}
\hline Chemical constituents $\mathrm{Mg} / \mathrm{l}$ & $\begin{array}{l}\text { Fresh water } \\
\text { (Onumiri Spring) }\end{array}$ & $\begin{array}{l}\text { Run-off water } \\
\text { (IMSU farm) }\end{array}$ & $\begin{array}{l}\text { Saltwater } \\
\text { (Abonnema river) }\end{array}$ \\
\hline Sodium, $\mathrm{Na}$ & 229.50 & 650.07 & 269.50 \\
\hline Potassium, $\mathrm{K}$ & 311.00 & 759.50 & 780.08 \\
\hline Calcium, $\mathrm{Ca}$ & 200.50 & 311.02 & 351.00 \\
\hline Sulphate, $\mathrm{SO}_{4}{ }^{2}$ & 14.80 & 19.54 & 20.35 \\
\hline Nitrate, $\mathrm{NO}_{3}^{-}$ & 0.13 & 0.14 & 0.19 \\
\hline Carbonate, $\mathrm{CO}_{3}^{-}$ & 269.50 & 450.05 & 5201.00 \\
\hline Bicarbonate, $\mathrm{HCO}_{3}^{-}$ & 261.00 & 969.70 & 1008.60 \\
\hline Chloride, $\mathrm{CL}^{-}$ & 219.50 & 270.05 & 322.00 \\
\hline Fluoride, $\mathrm{FL}^{-}$ & 1.09 & 1.64 & 1.73 \\
\hline Phosphate, $\mathrm{PO}_{4}^{-}$ & 27.54 & 38.40 & 40.05 \\
\hline Iron $\mathrm{Fe}$ & 1.29 & 1.83 & 1.89 \\
\hline Copper, $\mathrm{Cu}$ & 1.30 & 1.79 & 1.88 \\
\hline Manganesium, $\mathrm{Mg}$ & 0.89 & 1.13 & 1.49 \\
\hline Manganese, $\mathrm{Mn}$ & 1.09 & 1.32 & 1.51 \\
\hline $\mathrm{Zinc}, \mathrm{Zn}$ & 1.30 & 1.49 & 1.69 \\
\hline Lead, $\mathrm{Pb}$ & 0.12 & 1.21 & 1.43 \\
\hline $\mathrm{Cadmium}, \mathrm{Cd}$ & 0.10 & 1.38 & 1.70 \\
\hline $\mathrm{Acidity}$ & 0.07 & 0.13 & 0.16 \\
\hline $\mathrm{pH}$ & 6.69 & 9.58 & 9.84 \\
\hline
\end{tabular}

Except $\mathrm{pH}$ level of acidity, the unit is $\mathrm{mg} / \mathrm{l}$.

\subsubsection{Results Compressive Strength Tests}

The results of the compressive strength tests are shown in Table 2

Table2. Results of the Concrete Compressive Strengths with different Water Qualities

\begin{tabular}{|l|l|l|l|l|l|l|}
\hline S/no & Water type & Concrete Mix Ratio & Average Compressive Strength $\left(\mathrm{N} / \mathrm{mm}^{2}\right)$ & \\
\hline & & & 7 days & 14 days & 21 days & 28 days \\
\hline 1 & Fresh Water & $1: 2: 4$ & 21.74 & 24.97 & 27.02 & 30.88 \\
\hline 2 & Distilled Water & $1: 2: 4$ & 19.95 & 35.88 & 22.55 & 22.65 \\
\hline 3 & Run-off Water & $1: 2: 4$ & 20.76 & 28.00 & 24.75 & 22.50 \\
\hline 4 & Salt Water & $1: 2: 4$ & 32.95 & 33.77 & 28.60 & 21.85 \\
\hline
\end{tabular}

Cement/Water Ratio used in all cases is 0.5 


\subsubsection{Graph Showing the Variation of Compressive Strength with Age}

A graph of Compressive Strength and their Ages was plotted to increase the understanding of the variation between the compressive strength of concrete and their ages when produced with salt water, run-off and fresh water. This is illustrated in Figure 1

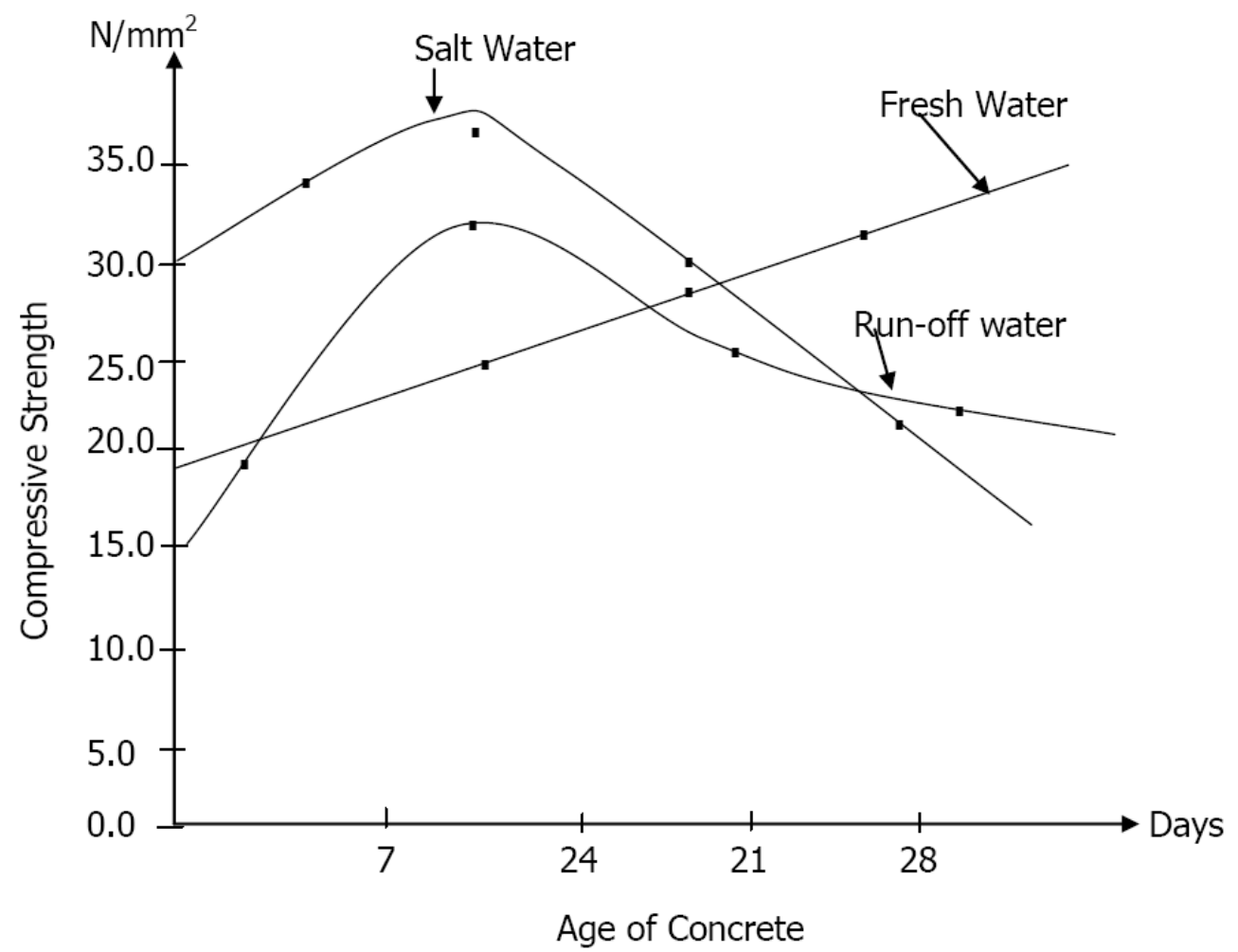

Figure1. Graph of compressive Strength against Age of Concrete.

\subsection{Discussion and Analysis}

The results gotten from the chemical analysis showed that the three water samples have different concentrations of chemical composition. From Table1, it can be observed that the salt water has the highest concentration of chlorides and carbonates as compared with fresh and run-off water. It is observed from the results that the fresh water has the least chemical concentrations as compared with fresh water and this makes it suitable for concrete mixing. The level of acidity, $\mathrm{pH}, \mathrm{CO}_{3}^{-}$and $\mathrm{HCO}_{3}^{-}$ of salt water were higher than that of run-off water. There were considerable presence of impurities in runoff water due to its flow movement within the delineated catchment area.

Table 2 and figure 1 show that the compressive strength of concrete cubes produced with fresh water increased enormously with age and this goes a long way to depict the suitability of fresh water for use in the production of concrete. With freshwater-produced concrete, there was a progressive increment in compressive strength from $21.74 \mathrm{~N} / \mathrm{mm}^{2}$ to $30.88 \mathrm{~N} / \mathrm{mm}^{2}$.It was discovered from Table 2 and figure 1 , that the compressive strength of concrete cubes produced with salt water and run-off water at early age of 14days tends to increase but later witnessed massive loss of compressive strength with its progression in age. The presence of such elements as $\mathrm{Na}, \mathrm{K}, \mathrm{Ca}, \mathrm{Cl}$ helped to increase the rate of hydration which facilitated the early compressive strength increment but it later witnessed drastic reduction due to their excessive quantities.

\section{CONCLUSION AND RECOMMENDATION}

\subsection{Conclusion}

Following the observations made in this empirical research, it can be concluded that concrete produced with fresh water gained appreciable strength with age. Though, there was slight decrease in the strength but later on, the strength became steady. The concrete produced with salt water increases its compressive at the 7days but later decreased drastically at the 14days, 21days and 28days. The salt water produced reinforced concrete will create an alarming resultant effect of corrosion on the reinforcement. 
Obi Lawrence E.

\subsection{Recommendations}

1. Portable or fresh water should always be employed in the production of concrete to enable it attain maximum compressive strength over time.

2. Salt water should not be used for concrete production unless adequate precautionary measures such as the protection of the reinforcement against rusting and chemical degradation.

3. All water intended to be used for production of concrete must be evaluated to make sure it conforms to the laid down standards.

4. Strict adherence should be given to specifications most especially in any issue concerning reinforced concrete structure.

\section{REFERENCES}

[1] Al-Manaseer, A.A., Haug, M.D. and Nasser, K.W. (1988), Compressive Strength of Concrete containing Fly- ash, Brine and Admixture, American Concrete Institute, Material Journal, 85(2): 109-116.

[2] Bella M. \&Fabuss, T. (1989), Properties of Seawater.1st Edition Academic PressBoston.

[3] Bryant. M. (1964), Effects of Seawater on Concrete, Miscellanous Paper no 6-690, U.S. Army Engineers, Waterways Experiment Station, Corps of Engineers Vicks Berg Mississipi.

[4] Chatveera. B., Lerwattanaruk, P. and Makul, N. (2006), Effect of Sludge Water from ReadyMixed Concrete Plant on Properties and Durability of Concrete, Elsevier, Cement and Concrete Composities, 28(5):441-450.

[5] Footes, P.G., \&Mettan, J.D. (1998), Concreted Deterioration and Corrosion of Steel in Marine Environment, Element and Concrete association.

[6] Ghorab, H.Y., Hilal, M.S. and Kishar, E.A. (1989), effect of Mixing and Curing Waters on the Behaviour of Cement Castes and Concrete. Part I: Microstructure of Cement Pastes, American Concrete Institute of Cement and Concrete Research. 19(6): 868-878.

[7] Gupta B.L. and Gupta Amid (2012), Concrete Technology, Standard Publishers 1td, India.

[8] Neville, A.M. (1996), Properties of Concrete, 4th Edition, ELBS Longman London, 1-50. 